\title{
The effect of cisplatin on human larynx carcinoma cell motility
}

\author{
Roman Paduch ${ }^{1}$, Wojciech Rzeski1,2, Janusz Klatka ${ }^{3}$ \\ ${ }^{1}$ Department of Virology and Immunology, Institute of Microbiology and Biotechnology, \\ Maria Curie-Skłodowska University in Lublin, Lublin, Poland \\ ${ }^{2}$ Department of Medical Biology, Institute of Agricultural Medicine in Lublin, Lublin, Poland \\ ${ }^{3}$ Department of Otolaryngology and Laryngeal Oncology, Skubiszewski Medical University of Lublin, \\ Lublin, Poland
}

\begin{abstract}
Head and neck tumors are one of the major public health problem all over the world. Cellular response of larynx carcinoma to cisplatin (CDDP) chemotherapy occurs both in cell-interdependent and cell-autonomous pathways. In the first pathway, cytotoxic signal transduction is mediated via gap-junctional intercellular communication (GIJC). CDDP also influence tumor cell migration. The aim of this study was the analysis of the effect of CDDP $(0.5 \mu \mathrm{g} / \mathrm{ml}$ and $1.5 \mu \mathrm{g} / \mathrm{ml})$ on the gap-junction intercellular communication and motility, respectively, in two new cell cultures (RK33 and RK45) derived from human larynx carcinoma. The migration of RK45 cell line was slightly inhibited and RK33 not affected after the incubation with CDDP. Tumor cells incubation with CDDP resulted in farther LY migration through neighboring cells beyond monolayer wound than in control cultures. In conclusion, there is a relationship between intercellular communication via gap junctions and motility of laryngeal tumor cells after CDDP application.
\end{abstract}

Key words: laryngeal carcinoma, cell culture, cisplatin, tumor cell motility

\section{Introduction}

Squamous cell carcinoma of the larynx is the major public health problem. Treatment of this cancer by chemotherapy applied until late 1970 s had a relatively poor response in patients. The use of cisplatin (CDDP) or cisplatin and 5-fluorouracil (5-FU) combination treatment regimens showed benefit results in chemosensitive laryngeal tumors [1,2]. CDDP is a chemotherapeutical agent exhibiting activity against many types of human malignancies including testicular and ovarian cancers or bladder, lung and head and neck tumors [3-5]. CDDP interacts with cellular proteins, lipids and forms covalent DNA adducts causing cell cycle arrest in phase $\mathrm{G} 2+\mathrm{M}$ $[3,4]$. Cellular response to CDDP action occurs both in cell-interdependent and cell-autonomous pathways. In cell-interdependent communication mechanisms, cytotoxic signal transduction, control of cell

Correspondence: R. Paduch, Maria Curie-Skłodowska

University, Institute of Microbiology and Biotechnology,

Dept. of Virology and Immunology, Akademicka 19 Str., 20-033

Lublin, Poland; tel.: (+4881) 5375942, fax.: (+4881) 5375940,

e-mail: rpaduch@poczta.umcs.lublin.pl proliferation, differentiation and apoptosis is mediated via gap-junctional intercellular communication (GIJC). Gap junctions (intercellular channels) are formed by protein subunits known as connexins, which oligomerize to the hexameric structure, the connexons [6,7]. Connexons from adjacent cells interact, forming intercellular channels which cluster in specialized membrane regions called gap junctions. Through these channels, molecules exchange among neighboring cells without secreting them into the extracellular space [6].

In the present study we analysed cisplatin action on the motility and gap-junction intercellular communication in two new cell cultures (RK33 and RK45) derived from human laryngeal carcinoma.

\section{Materials and methods}

Cell cultures. RK33 and RK45 cell lines were characterized in our previous study [8]. RK33 cell line was established from a tumor fragment at T3 stage taken from 50-years old woman after laryngectomy. RK45 cell line was established from a tumor fragment at T3 stage obtained from a 61-years old man. Cultures were kept at $37^{\circ} \mathrm{C}$ in a humidified atmosphere with $5 \% \mathrm{CO}_{2}$. Cells were subcultured to $25 \mathrm{~cm}^{2}$ tissue culture flasks (Nunc.) using $0.25 \%$ trypsin-EDTA (Sigma) solution. 
MTT assay. Sensitivity of cells to CDDP $(0.5 \mu \mathrm{g} / \mathrm{ml}$ and $1.5 \mu \mathrm{g} / \mathrm{ml}$ ) was determined by a standard spectrophotometric 3-(4,5-dimethylthiazole-2-yl)-2,5-diphenyltetrazolium bromide (MTT) assay. Cells grown in 96-well multiplates in $100 \mu 1$ of culture medium supplemented with $2 \%$ FBS were incubated for $3 \mathrm{~h}$ with MTT solution $(5 \mathrm{mg} / \mathrm{ml}, 25 \mu \mathrm{l} /$ well) (Sigma). The yellow tetrazolium salt was metabolized by viable cells to purple crystals of formazan. The crystals were solubilized overnight in a solution consisting of $10 \%$ sodium dodecyl sulfate (SDS) (Sigma) in $0.01 \mathrm{M} \mathrm{HCl}$. The product was quantified spectrophotometrically by absorbance measurement at $570 \mathrm{~nm}$ wavelength using an E-max Microplate Reader (Molecular Devices Corporation, Menlo Park, CA, USA).

Neutral red (NR) uptake assay. Cells were grown in 96-well multiplates in $100 \mu \mathrm{l}$ of culture medium (RPMI 1640) supplemented with $2 \%$ FBS and CDDP $(0.5 \mu \mathrm{g} / \mathrm{ml}$ and $1.5 \mu \mathrm{g} / \mathrm{ml})$. Subsequently, the medium was discarded and $0.4 \%$ NR (Sigma) solution in $2 \%$ FBS medium was added to each well. The plate was incubated for $3 \mathrm{~h}$ at $37^{\circ} \mathrm{C}$ in a humidified $5 \% \mathrm{CO}_{2} / 95 \%$ air incubator. After incubation, the dye-containing medium was removed, cells fixed with $1 \% \mathrm{CaCl}_{2}$ in $4 \%$ paraformaldehyde and thereafter the incorporated dye was solubilized using $1 \%$ acetic acetate in $50 \%$ ethanol solution $(100 \mu 1)$. The plates were gently shacked for $20 \mathrm{~min}$ at room temperature and the extracted dye absorbance was spectrophotometrically measured at $540 \mathrm{~nm}$.

Cell migration assessment. Tumor cell migration was assessed in the wound assay model as previously described [9]. Tumor cells were plated at $1 \times 10^{6}$ cells on $4 \mathrm{~cm}$ culture dishes (Nunc). Next day, the cell monolayer was scratched by the pipette tip (P300), the medium and dislodged, cells were aspirated and the plates rinsed twice with PBS. Next, the fresh culture medium was applied and the number of cells migrated into the wound area after 24 hours was estimated in the control and the cultures treated with cisplatin $(1.5 \mu \mathrm{g} / \mathrm{ml})$. The plates were stained with the May-GrünwaldGiemsa method. The observation was performed in Olympus BX51 System Microscope (Olympus Optical CO., LTD, Tokyo, Japan) and the micrographs were prepared in analySIS ${ }^{\circledR}$ software (Soft Imaging System GmbH, Münster, Germany). Cells migrated to the wound area were counted on micrographs and results expressed as a mean cell number migrated to the selected 50 wound areas taken from 4 micrographs.

Lucifer Yellow dye transfer through gap junction channels assay. Tumor cells were plated on Petri dishes at a density of $1 \times 10^{5}$ cells $/ \mathrm{ml}$ for 2 days. When cells reached confluence, the medium was removed and cells were exposed for $24 \mathrm{~h}$ to CDDP $(0.5 \mu \mathrm{g} / \mathrm{ml})$ in RPMI 1640 medium containing $2 \%$ FCS. Thereafter, the medium was discarded and $0.5 \mathrm{mg} / \mathrm{ml}$ Lucifer Yellow $\mathrm{CH}$ lithium salt solution was added to the cell monolayers. Using a sterile scalpel blade a wound cells (monolayer scarification) was performed in a straight line. The plate was left for $3 \mathrm{~min}$ in dark for complete dye-loading transfer to adjacent cells, rinsed with PBS containing $\mathrm{Ca}^{2+}$ and $\mathrm{Mg}^{2+}$ and fixed with $4 \%$ (v/v) formaldehyde. Plates were analyzed in a fluorescent Olympus BX51 microscope with UV light source and micrographs were prepared using AnalySIS software.

Statistical analysis. Results are presented as means \pm SD. Data were analyzed with t-student's test. Differences of $p<0.05$ were considered significant.

\section{Results}

In our previous study [8] we reported a successful establishment of two cell lines (RK33 and RK45) derived from two laryngeal carcinomas. Both cell lines exhibited similar sensitivity to etoposide, thiotepa and methotrexate. The present study was performed to analyze the chemosensitivity of these cell lines to CDDP and the effect of the drug on cells migration capacity and cellular communication via gap junctions. Viability of tumor cells were above $94 \%$ after $24 \mathrm{~h}$ incubation with $1.5 \mu \mathrm{g} / \mathrm{ml} \mathrm{CDDP}$ and $98 \%$ with $0.5 \mu \mathrm{g} / \mathrm{ml}$ CDDP as measured by MTT and NR uptake assay. In LY method we used lower CDDP concentration $(0.5 \mu \mathrm{g} / \mathrm{ml})$ to analyze only changes in dye migration through connexons after CDDP application without any disturbances associated with CDDP influence on cell membrane lipids and proteins.

The effect of CDDP on RK33 and RK45 tumor cells motility was assessed by means of the wound assay (Fig.1). The assay revealed that similar amounts of tumor RK33 cells migrated to the wound area in control and CDDP exposed cultures (Table 2). However, CDDP treatment caused less number of RK45 cells migrated to the wound area in comparison to control but the differences were not significant (Table 1).

Gap junctions cellular communication was tested using Lucifer Yellow (LY) dye (Mm $457 \mathrm{Da}$ ) which easily passes through connexon channels. Cells loaded with the dye diffuse it to another via gap junctions. LY is brightly fluorescent and its migration can be visualized under UV light sourced microscope. The results are shown in Fig. 2. Incubation of tumor cells with CDDP resulted in farther LY migration through neighboring cells beyond monolayer wound than in control cultures. The LY migration distance in CDDP treated cultures was significant in both cell lines in comparison with appropriate controls; RK33 ( $<<0.01)$, RK45 $(\mathrm{p}<0.05)$ as analyzed by t-student's test.

\section{Discussion}

This study presents the relationship between the motility of laryngeal carcinoma cells and intercellular communication via gap junctions after CDDP treatment.

CDDP is a well established chemotherapeutic agent used in the treatment of many cancers, also head and neck tumors. However, mechanisms of platinum resistance may reduce a therapeutic effects of this drug [10]. The main criterion of $0.5 \mu \mathrm{g} / \mathrm{ml}$ and $1.5 \mu \mathrm{g} / \mathrm{ml}$ of CDDP doses selection was based on their slight influence on laryngeal tumor cell viability but measurably effects on tumor cells functions. Moreover, in our previous study [11] we showed that $0.5 \mu \mathrm{g} / \mathrm{ml}$ of CDDP significantly increase P53 with simultaneous decreases in BCL-2 proteins expression. We also found that CDDP in this dose increase syndecan-1 expression in laryngeal cancers what may influence on tumor cells adhesive properties and possibility of metastasis occurrence [12]. 


\section{RK33}
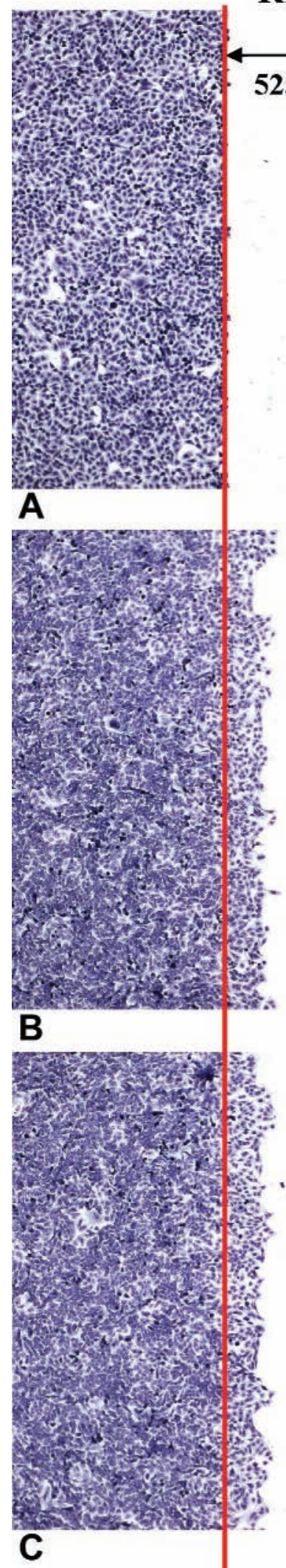

\section{RK45}


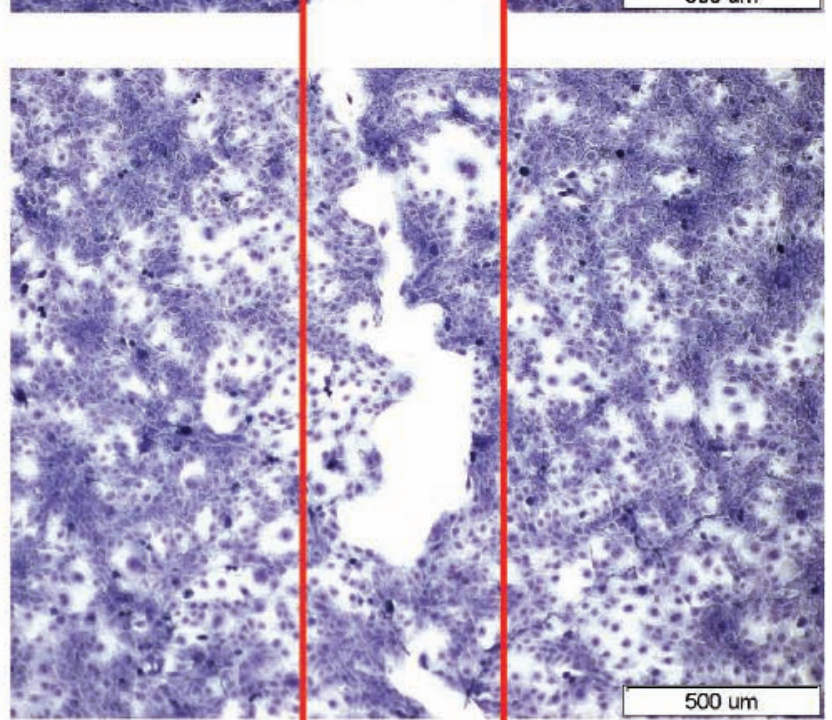

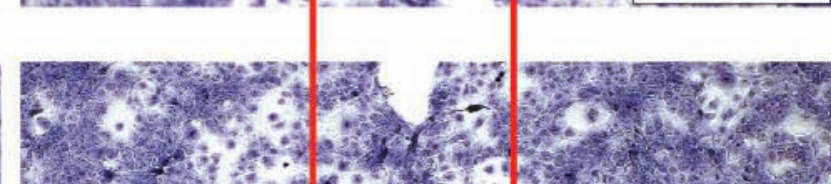
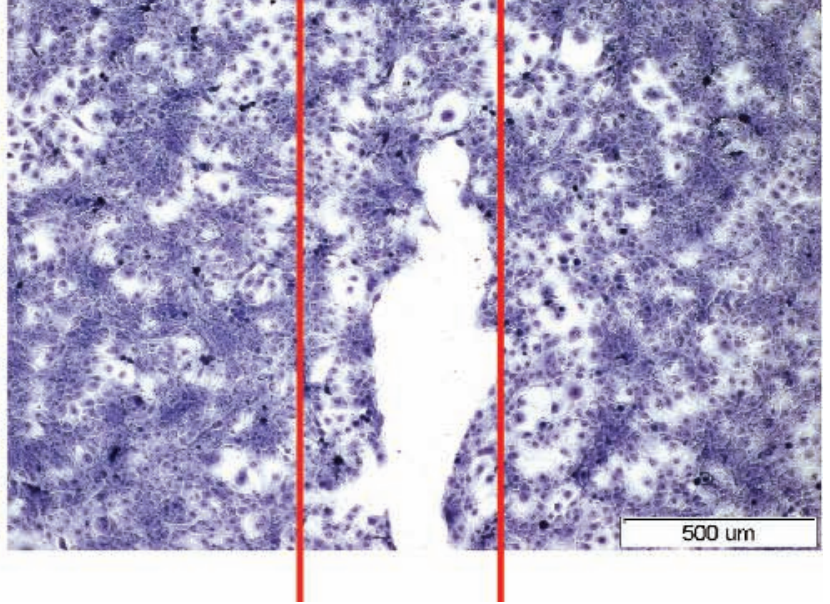

Fig. 1. The effect of cisplatin on the migration capacity of tumor cells in wound assay. (A) Wounded monolayer of RK33 and RK45 cell lines. (B)Tumor cell migration after $24 \mathrm{~h}$ in control cultures. (C) Tumor cell migration after $24 \mathrm{~h}$ incubation with $1.5 \mu \mathrm{g} / \mathrm{ml}$ cisplatin (bar $500 \mu \mathrm{m}$, original magnification $\times 40)$. 


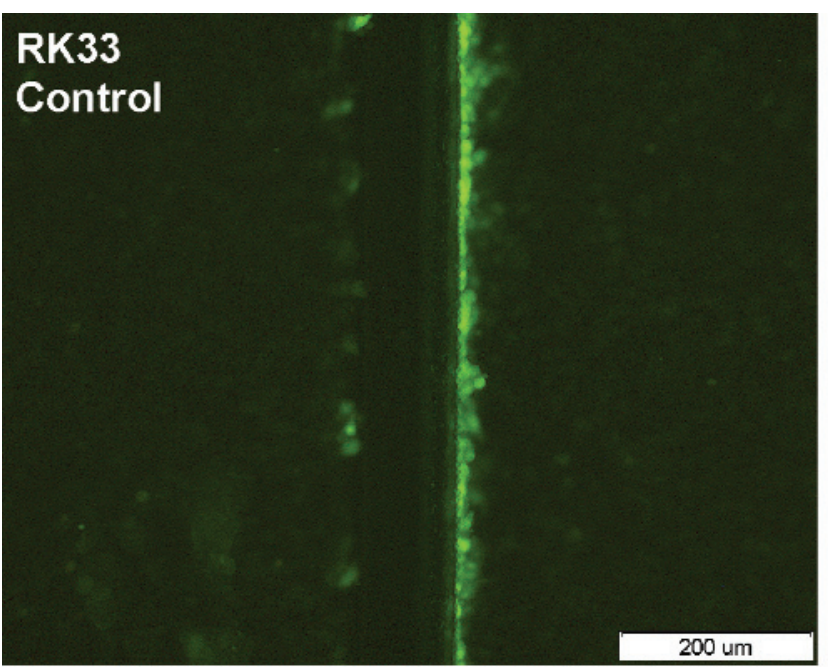

Dye migration distance $22.2 \pm 7.9 \mu \mathrm{m}$
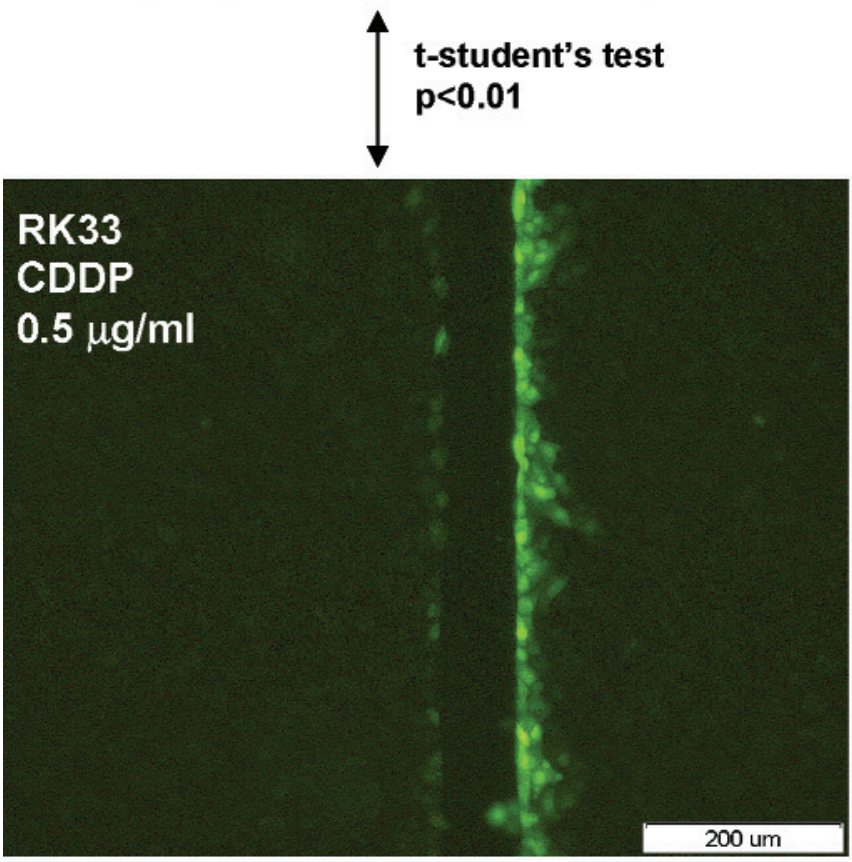

Dye migration distance $34.7 \pm 10.9 \mu \mathrm{m}$



Dye migration distance $39.2 \pm 9.2 \mu \mathrm{m}$
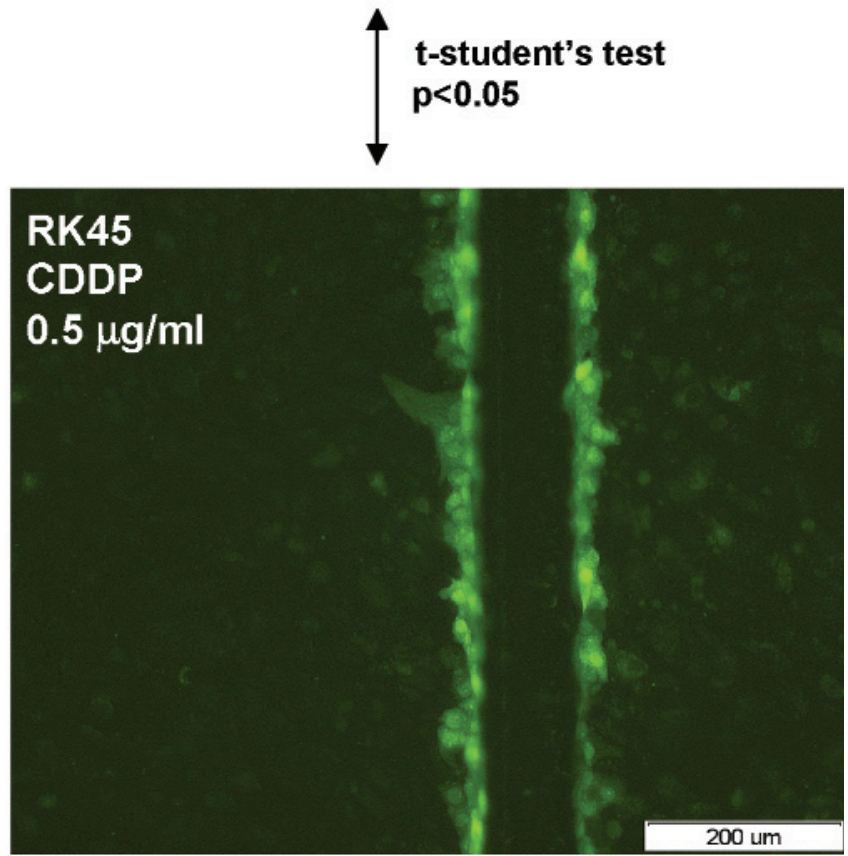

Dye migration distance $44.1 \pm 8.1 \mu \mathrm{m}$

Fig. 2. The effect of cisplatin $(0.5 \mu \mathrm{g} / \mathrm{ml})$ on fluorescent dye Lucifer Yellow (LY) diffusion via connexon channels in RK33 and RK45 larynx tumor cell lines. LY is brightly fluorescent dye (Mm $457 \mathrm{Da})$, easily passing through connexon channels to other adjacent cells. The migration distance is visualized under UV light sourced microscope. The LY migration distance in CDDP treated cultures was significant in both cell lines in comparison with the appropriate controls; RK33 (p<0.01), RK45 $(\mathrm{p}<0.05)$ as analyzed by t-student's test (bar $200 \mu \mathrm{m}$, original magnification $\times 100$ ).

Table 1. Tumor cells migration in wound assay. Results are expressed as mean number of cells migrated per field of the wound area $\pm \mathrm{SD}$ of 50 measurements.

\begin{tabular}{|c|c|c|}
\hline Cell culture & Control & $\begin{array}{c}\text { CDLP }(1.5 \mu \mathrm{g} / \mathrm{ml}) \\
\text { treated cells }\end{array}$ \\
\hline RK33 & $36.7 \pm 1.8$ & $36.63 \pm 3.66$ \\
\hline RK45 & $40.85 \pm 5.89$ & $37.54 \pm 5.79$ \\
\hline
\end{tabular}

Our observations revealed that RK33 cells were more sensitive to CDDP action than RK45. However, this did not affect the migration of RK33 cells but limited gap junction communication as compared with RK45 cells. On the other hand, CDDP reduced amount of migrating RK45 cells, that was associated with better intercellular communication in comparison with RK33 cell line.

Taken together, the results of our study demonstrate that there may be an important role of gap junctions in 
mediating CDDP killing and inhibiting migration of tumor cells. Our results are in consistence with Jensen and Glazer [13] who showed that cell-interdependent pathway plays a substantial role in the overall cell killing only if there is a sufficient cell-to-cell contact and GJIC are functional. In low drug concentrations, inhibiting of cell migration may be observed. On the other hand, cytotoxicity of CDDP in RK33 cell line could occur via cell-autonomous basis, where unrepaired platinum-DNA adducts blocked transcription and replication. It also could be a result of less strict monolayer formation by RK33 cells than RK45. Moreover, Lee at al. [14] indicated that connexins may function as tumor suppressor genes. Therefore, the better intracellular communication and in consequence toxic metabolites or low molecular drugs exchange via gap junctions, the more markedly visible inhibition of tumor cells growth [14]. It was also shown that downregulation of connexin43 increased resistance to CDDP of human wild-type cancer cell lines. Other experiments revealed that cytotoxic or inhibitory signals can be transmitted to neighboring cells but not to cells deficient in GJIC [13].

Summing up, it seems that our results are in consistence with results of other authors who show that the response of laryngeal tumor cells to CDDP occurs through cell-interdependent and cell-autonomous pathways. However, gap junction cellular communication is the most important in mediating cell migration inhibitory signals. Our results showed that laryngeal carcinoma cell lines derived from tumors of two patients exhibit different sensitivity to CDDP action. We found the differences in cell motility and diffusion of the fluorescent dye Lucifer Yellow via connexon channels connecting the adjacent cells. Therefore, the examination of gap junction expression among tumor cells may be helpful in limiting the invasiveness of tumor cells.

\section{References}

[1] Devlin JG, Langer CJ. Combined modality treatment of laryngeal squamous cell carcinoma. Expert Rev Anticancer Ther. 2007;7:331-350.

[2] Richard JM, Sancho-Garnier H, Pessey JJ, Luboinski B, Lefebvre JL, Dehesdin D, Stromboni-Luboinski M, Hill C.
Randomized trial of induction chemotherapy in larynx carcinoma. Oral Oncol. 1998;34:224-228.

[3] Jakubowicz-Gil J, Paduch R, Gawron A, Kandefer-Szerszeń M. The effect of cisplatin, etoposide and quercetin on Hsp72 expression. Pol J Pathol. 2002;53:133-137.

[4] Jakubowicz-Gil J, Paduch R, Gawron A, Kandefer-Szerszeń M. The effect of heat shock, cisplatin, etoposide and quercetin on Hsp27 expression in human normal and tumour cells. Folia Histochem Cytobiol. 2002;40:31-35.

[ 5] Paduch R, Słotwińska M, Stachura A, Rzeski W, Zdzisińska B, Kandefer-Szerszeń M. Comparative analysis of different methodological approaches to the in vitro study of tumour cells chemosensitivity. Ann Univ Mariae Curie-Sklodowska [Biol]. 2001;LVI:7-19.

[6] Bruzzone R, White TW, Paul DL. Connections with connexins: the molecular basis of direct intercellular signaling. Eur $J$ Biochem. 1996;238:1-27.

[ 7] Procházka L, Turánek J, Tesařik R, Knotigová P, Polášková $P$, Andrysík Z, Kozubík A, Žák F, Sova P, Neuzil J, Machala M. Apoptosis and inhibition of gap-junctional intercellular communication induced by LA-12, a novel hydrophobic platinum(IV) complex. Arch Biochem Biophys. 2007;462:54-61.

[ 8] Rzeski W, Paduch R, Klatka J, Kandefer-Szerszeń M, Stepulak A, Pożarowski P, Zdzisińska B. Establishment and preliminary characterization of two cell lines derived from larynx carcinoma. Folia Histochem Cytobiol. 2002;40:195-196.

[9] Rzeski W, Matysiak J, Kandefer-Szerszeń M. Anticancer, neuroprotective activities and computational studies of 2amino-1,3,4-thiadiazole based compound. Bioorg Med Chem. 2007; 15:3201-3207.

[10] Wernyj RP, Morin PJ. Molecular mechanisms of platinum resistance: still searching for the Achilles' heel. Drug Resist Updates. 2004;7:227-232.

[11] Klatka J, Paduch R, Pożarowski P, Pietruszewska W, Kupisz K, Trojanowski P, Roliński J. Application of primary cell cultures of laryngeal carcinoma and laser scanning cytometry in the evaluation of tumor reactivity to cisplatinum. Folia Histochem Cytobiol. 2008;46:159-164.

[12] Klatka J, Paduch R, Pożarowski P, Borzęcka H, Rogowski M. Expression of syndecan-1 in primary cultures of laryngeal carcinoma cells after the incubation with cisplatin. Pol J Environ Stud. 2005;14,Suppl II:202-205.

[13] Jensen R, Glazer PM. Cell-interdependent cisplatin killing by $\mathrm{Ku} / \mathrm{DNA}$-dependent protein kinase signaling transduced through gap junctions. Proc Natl Acad Sci USA. 2004; 101:6134-6139.

[14] Lee SH, Tomasetto C, Paul D, Keyomarsi K, Sager R. Transcriptional down-regulation of gap-junction proteins blocks junctional communication in human mammary tumor cell lines. J Cell Biol. 1992;118:1213-1221.

Submitted: 20 May, 2008 Accepted after reviews: 5 November, 2008 